\title{
Towards Quantitative Prediction of Mechanical Properties of Tandem Modular Elastomeric Protein-based Hydrogels
}

\author{
Linglan $\mathrm{Fu}$ and Hongbin $\mathrm{Li}^{*}$
}

\section{Supporting Information}

\author{
Amino acid sequences of the engineered elastomeric proteins \\ (GR) 4 : \\ MVDGGS(MDTYKLILNGKTLKGETTTEAVDAATAEKVFKQYANDNGVDGEWTYDDATKTFTVTERSGGR \\ PSDSYGAPGGGNRS) $)_{4}$ GGTELKLAAALEHHHHHH \\ (GR): \\ MVDGGS(MDTYKLILNGKTLKGETTTEAVDAATAEKVFKQYANDNGVDGEWTYDDATKTFTVTERSGGR \\ PSDSYGAPGGGNRS) ${ }_{8}$ GGTELKLAAALEHHHHHH \\ $(\mathrm{GR})_{12}$ : \\ MVDGGS(MDTYKLILNGKTLKGETTTEAVDAATAEKVFKQYANDNGVDGEWTYDDATKTFTVTERSGGR \\ PSDSYGAPGGGNRS) ${ }_{12}$ GGTELKLAAALEHHHHHH \\ $(\mathrm{GR})_{16}$ : \\ MVDGGS(MDTYKLILNGKTLKGETTTEAVDAATAEKVFKQYANDNGVDGEWTYDDATKTFTVTERSGGR \\ PSDSYGAPGGGNRS) ${ }_{16}$ GGTELKLAAALEHHHHHH \\ $(\mathrm{GR})_{12}$-Spycatcher: \\ MVDGGS(MDTYKLILNGKTLKGETTTEAVDAATAEKVFKQYANDNGVDGEWTYDDATKTFTVTERSGGR \\ PSDSYGAPGGGNRS) ${ }_{12}$ GAMVDTLSGLSSEQGQSGDMTIEEDSATHIKFSKRDEDGKELAGATMELRDSSGK \\ TISTWISDGQVKDFYLYPGKYTFVETAAPDGYEVATAITFTVNEQGQVTVNGKATKGDAHIGGTELKLAA \\ ALEHHHHHH \\ (GR) $)_{12}$-Spytag: \\ MVDGGS(MDTYKLILNGKTLKGETTTEAVDAATAEKVFKQYANDNGVDGEWTYDDATKTFTVTERSGGR \\ PSDSYGAPGGGNRS) ${ }_{12}$ AHIVMVDAYKPTKGGTELKLAAALEHHHHHH \\ (GB1) : \\ MRGSHHHHHHGS(MDTYKLILNGKTLKGETTTEAVDAATAEKVFKQYANDNGVDGEWTYDDATKTFTV \\ TERS $)_{8}$ \\ (FL) $)_{8}$ : \\ MRGSHHHHHHGS(MGEFDIRFRTDDDEQFEKVLKEMNRRARKDAGTVTYTRDGNDFEIRITGISEQNRKEL \\ AKEVERLAKEQNITVTYTERGSLERS) 8
}




\section{$(G R)_{n}$-based hydrogels are stable}

The chemically crosslinked $(\mathrm{GR})_{\mathrm{n}}$ hydrogels are stable in their native and denatured states, and no erosion was observed for two days, suggesting that almost all (GR) 12 polyproteins were crosslinked in the hydrogel network. This conclusion was further corroborated by tensile testing of the hydrogels in the native and denatured states. When cycled between native and denatured states, the Young's moduli of the native and denatured states remained largely unchanged in their respective states (Fig. S2).

\section{Determining the shear modulus $G$ from stress-strain curves}

There are two ways of determining the shear modulus $G$ from stress-strain curves: one is to directly calculate $G$ using the relationship $G=E / 3$, where $E=\partial \sigma / \partial \lambda$ when $\lambda=1$. In our experiments, $E$ is determined from $\lambda=1-1.05$ (corresponding to strain of $0-5 \%$ ). The second method is to plot $\sigma$ versus $\lambda-1 / \lambda^{2}$. According to $\sigma=G\left(\lambda-\frac{1}{\lambda^{2}}\right)=\frac{\rho R T}{\overline{M_{c}}}\left(\lambda-\frac{1}{\lambda^{2}}\right), \quad \sigma$ versus $\lambda-1 / \lambda^{2}$ should yield a straight line with a slope equal to $G$ for an ideal elastomer. ${ }^{1,2}$ For our native (GR)n hydrogels, the linear region is up to a $\lambda$ of $\sim 1.1$. The two methods yielded shear modulus $G$ that are of similar values.

\section{References}

1. Elvin, C. M.; Carr, A. G.; Huson, M. G.; Maxwell, J. M.; Pearson, R. D.; Vuocolo, T.; Liyou, N. E.; Wong, D. C.; Merritt, D. J.; Dixon, N. E., Synthesis and properties of crosslinked recombinant pro-resilin. Nature 2005, 437, 999-1002.

2. Treloar, L. R. G., The physics of rubber elasticity. Oxford University Press, USA: 1975. 


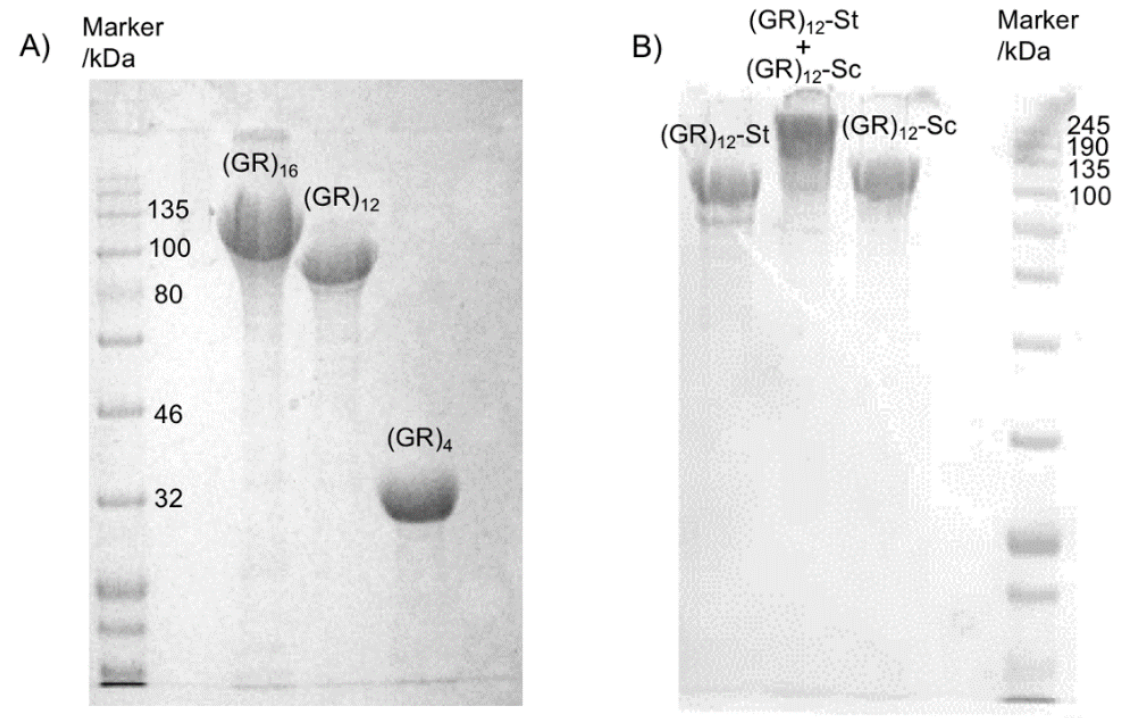

Figure S1. A) 10\% Sodium dodecyl sulfate-polyacrylamide gel electrophoresis (SDS-PAGE) photographs of purified $(\mathrm{GR})_{4},(\mathrm{GR})_{12},(\mathrm{GR})_{16}$. B) 10\% SDS-PAGE picture of (GR) ${ }_{12}$-SpytagSpycatcher-(GR) ${ }_{12}\left(1: 1\right.$ molar ratio mix), purified $(\mathrm{GR})_{12}$-Spytag, $(\mathrm{GR})_{12}$-Spycatcher. 

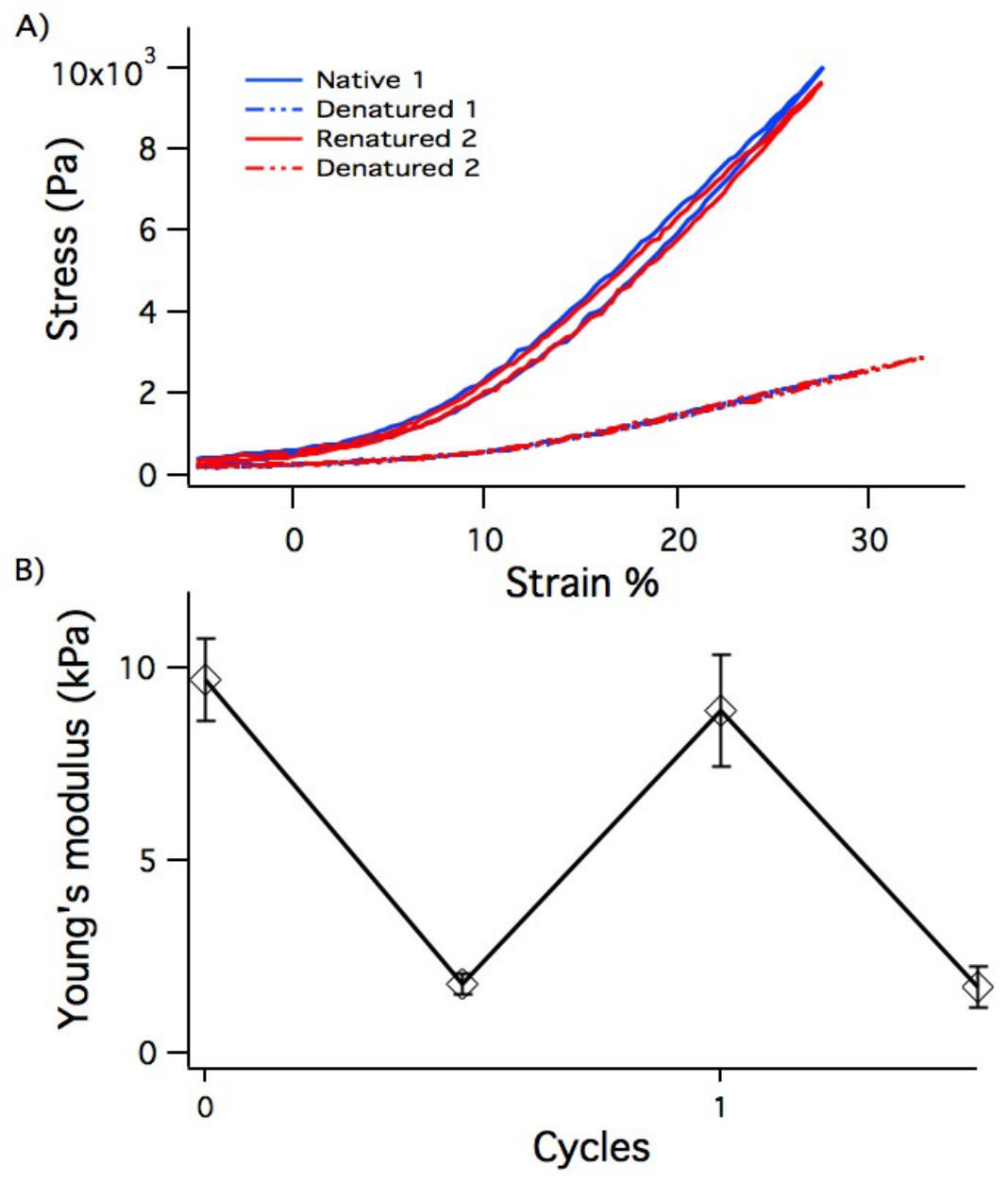

Figure S2. A) Representative stress-strain curves of $20 \%(\mathrm{GR})_{12}$ hydrogels cycled between native and denatured states (Native1-Denatured1-Renatured2-Denatured2). B) Change of the Young's modulus of $20 \%(\mathrm{GR})_{12}$ hydrogels in consecutive native-denatured cycles. Error bars indicate the standard deviation. For each data point, $\mathrm{n}=3$. 
A)
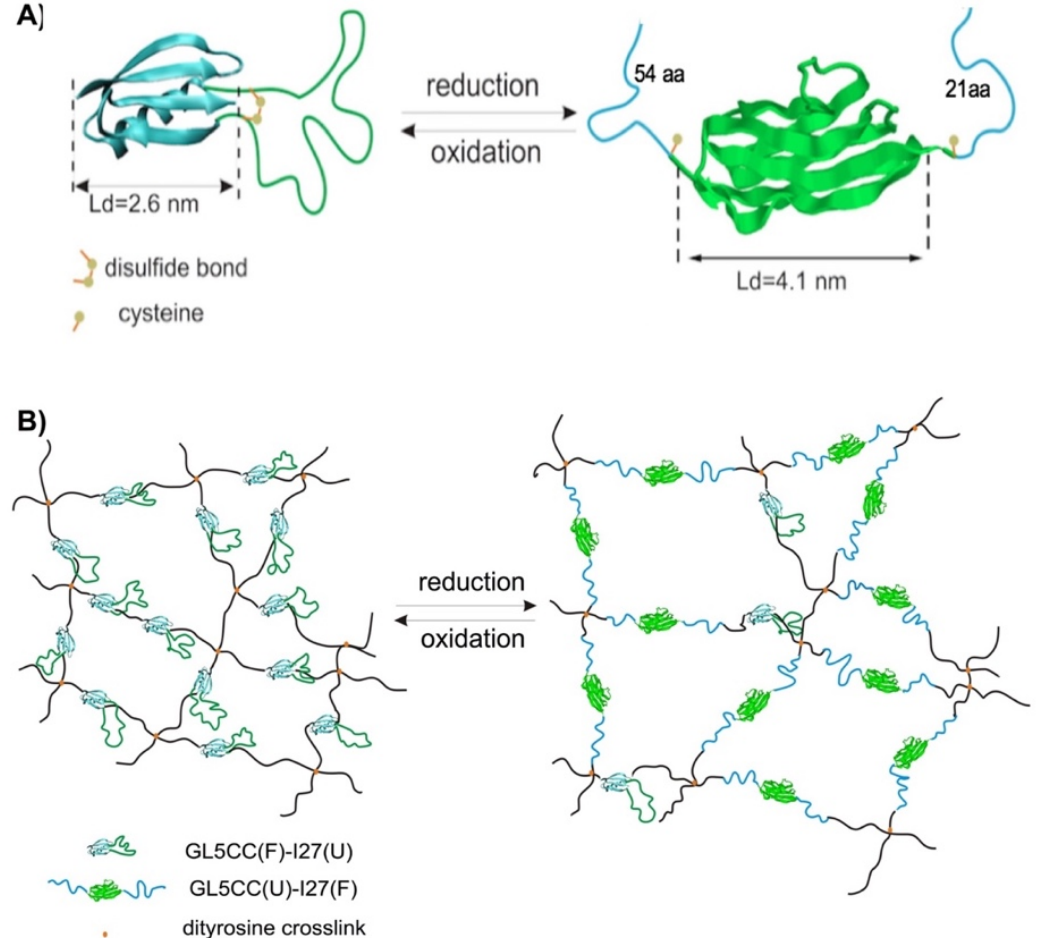

C)

\begin{tabular}{|c|c|c|c|c|c|}
\hline & & $\begin{array}{c}M_{w e} \\
(\mathrm{kDa})\end{array}$ & $\begin{array}{c}\text { Predicted } \\
E_{\text {oxidized }} / E_{\text {reduced }}\end{array}$ & $\begin{array}{c}E \\
(\mathrm{kPa})\end{array}$ & $\begin{array}{c}\text { Experimental } \\
E_{\text {oxidized }} / E_{\text {reduced }}\end{array}$ \\
\cline { 1 - 3 } G-R-(G- & oxidized & 10.4 & \multirow{2}{*}{2.6} & $9.0 \pm 0.9$ & \multirow{2}{*}{3.2} \\
\cline { 2 - 3 } MEP-R) & reduced & 27.1 & 2.6 & $2.8 \pm 0.4$ & \\
\hline
\end{tabular}

Figure S3. Using length equivalent molecular weight approach to predict the change of the mechanical properties of MEP-based dynamics hydrogels. A) Schematic showing the MEP-based, redox-responsive folding switch. B) Schematics of the MEP-based dynamic protein hydrogel. C) Prediction of $E_{\text {oxidized }} / E_{\text {reduced }}$ based on $M_{\text {we }}$ A) and B) are adapted from Ref. 37. 